\section{A importância das teorias éticas na prática da bioética}

\section{The importance of ethical theories in the bioethics' practice}

Helena Maria Carneiro Leão 1
1 Programa de Doutoramento em Bioética. Faculdade de Medicina. Universidade do Porto. Alameda Prof. Hernâni Monteiro, 4200319. Porto, Portugal. E-mail: helenacleao@hotmail.com

\begin{abstract}
The knowledge search without limits and the concern of practicing abuses and exaggerations as a result of curiosity divide the human behavior. The ethical theory comes from the need for rational justification of moral actions, toward the own human conscience and other people. As the theory consists of an integrated complex of ethical, coherent and fundamental principles, the ethical theories knowledge is essential for the reflection, especially when is not possible to fulfill all moral requests. The bioethics, originally considered source of general norms and rules for disciplining ethically the scientific investigation, can be regard as a sort of professional ethical code to scientists and researchers, being a group of moral and philosophical reflection concerning life in general and medical practices in particular. In this article, by a literature review, it was aimed to describe and discuss the importance of ethical theories in the bioethics' practice.
\end{abstract}

Key words Ethical theories, Morale, Bioethics

\section{Resumo}

A busca sem limites do conhecimento e a preocupação com o cometimento de abusos e exageros nascidos da curiosidade dividem a conduta do homem. A teoria ética nasce da necessidade de justificar racionalmente as condutas morais, diante da própria consciência e diante dos demais. Por ser a teoria um complexo integrado de principios éticos, coerentes e fundamentais, o conhecimento das teorias éticas é essencial para reflexão, especialmente quando parece impossível cumprir todas as exigências de moralidade. A bioética, originalmente considerada fonte de normas e regras gerais para disciplinar eticamente a investigação científica, constituise uma espécie de código de ética profissional para os cientistas e pesquisadores, tornando-se um conjunto de reflexões filosóficas e morais sobre a vida em geral e sobre as práticas médicas em particular. Neste artigo, através de uma revisão da literatura, buscou-se descrever e discutir a importância das teorias éticas na prática da bioética.

Palavras-chave Teorias éticas, Moral, Bioética 


\section{Introdução}

Compreender a ética significa buscar a conduta do homem no meio social, isto é, o conjunto de preceitos ou regras através das quais pode ser fixado o seu comportamento na sociedade, partindo-se da visão de que é ela desenvolvida através de exigências de condutas pessoais e interpessoais, que progressivamente convertem-se em regras de estruturação de moralidade externa de comportamentos e formas de vida.

A ética é um saber positivo que, traçando efetivos regramentos de moral social, ensina e impõe o viver dentro de padrões respeitáveis de conduta na medida em que busca utilizar os bens sadios que sustentam a vida. É a ciência do comportamento moral do homem na sociedade, e, como tal, não pode ser entendida racionalmente, a não ser partindo-se de uma concepção filosófica.

Não sendo a sociedade estática e estando sempre na busca de novos conhecimentos a serem utilizados em benefício do próprio homem, os desenvolvimentos científicos, tecnológicos e sociais no século $\mathrm{XX}$ trouxeram grandes avanços, principalmente no campo das ciências biológicas. Isto levou ao surgimento da bioética e impôs novas concepções das obrigações éticas dos médicos na sociedade.

As mudanças culturais e políticas das décadas de 1950 e 1960, com uma cultura baseada em novos conceitos de liberdade, igualdade e justiça, contribuíram para surgimento e rápida autonomia das novas conquistas, ampliando conceitos e trazendo maior comprometimento dos médicos para com a sociedade.

Evidenciou-se, cada vez mais, uma abrangência generalizante (global) da medicina, onde as questões éticas passaram a estar ligadas com a própria vida em seu conceito primário, e após, o surgimento da bioética e das questões biomédicas, com a abordagem de problemas complexos e com a indispensável visão interdisciplinar, uma nova visão passou a ser contemplada pelos os estudiosos.

$\mathrm{O}$ agrupamento de doutrinas morais contempladas pela ética não pode mais ser confiada a uma visão ortodoxa, mas estudada através da contemplação de aspectos fornecidos por determinadas teorias, tornando possível a existência de um corpo integrado de princípios fundamentais, no qual se leve em conta a coerência, a justificativa e a viabilidade. Sendo assim, a ética passará a designar, como atualmente, uma estreita relação "com o que se passa", regrando situações históricas, conhecimentos científicos e valores sociais, permitindo uma visão reflexiva capaz de acompanhar os avanços e conquistas tecnológicas e biológicas.

O homem, na sua atividade social, postando-se ora sob a ótica do pesquisador, ora sob a de paciente, está dividido entre a fascinação por novas descobertas e o dever de respeito à autonomia e a dignidade humana.

A pesquisa médica não pode desconhecer limites à sua investigação, para que assim seja evitado o cometimento de abusos e exageros nascidos da curiosidade humana. Portanto, a busca de novos conhecimentos científicos estará sempre pautada em benefício ao ser humano e à sociedade.

\section{Ética: de Sócrates à época contemporânea}

Nas origens da nossa civilização, o nascimento da ética teve lugar na sequência de uma evolução do espírito grego, análoga a que se verifica em nosso tempo. Ela acompanhou a transformação da sociedade arcaica nas cidades industriosas e democráticas da Jônia e da Ática, tendo Atenas à sua frente. No fio dessa evolução apresenta-se, em primeiro lugar, o problema do trabalho e da riqueza, depois o problema da cultura e, finalmente, o problema do "bem agir" e do "bem viver" ou da ética. 1

O nascimento da filosofia é representado pelos "primeiros filósofos". As aspas entre as quais se encontra a expressão remetem a um problema. $\mathrm{Na}$ historiografia filosófica, esses homens dos séculos VI e V a.c. são comumente chamados de présocráticos, ou seja, aqueles que viveram antes de Sócrates. Nesse primeiro período, já havia preocupação com os problemas do homem, em especial os políticos e morais, e houve o surgimento do "sofismo", movimento intelectual na Grécia no século V a.c. Os sofistas se transformaram em mestres que ensinavam principalmente a arte de convencer através da persuasão. Porém, sob a designação temporal de pré-socráticos, aparentemente isenta - na verdade, incorreta - esconde-se, porém, uma (des) valorização, pois, se acordo com ela, eles seriam apenas precursores. A "verdadeira" filosofia começaria, segundo esse ponto de vista, apenas com Sócrates, para atingir seu apogeu com Platão e Aristóteles. ${ }^{2}$

A época hipocrática primitiva, do século $\mathrm{V}$ a.c., mostra-se completamente alheia aos ideais do humanismo médico tradicional. Não é uma ética de atenção ou cuidado do paciente, mas uma ética de resultados ou êxitos técnicos: o amor ao homem em decorrência do amor à arte, ou seja, a filantropia como consequência da filotecnia, corroborado pelo aforismo: "onde existe amor ao homem, há amor a arte”. Por essa época, as regras de conduta do 
médico ajustavam-se à moral da eficácia profissional, proporcionando-lhe tanto prestígio que, à semelhança dos demais artesãos gregos, o médico só poderia ser julgado em razão da perícia na arte de curar. $^{3}$

A influência das escolas filosóficas gregas determina o início da incorporação do humanismo à arte médica, em que o juramento hipocrático voltado a dignificar a ciência médica para proteção do paciente e da sociedade, representa elemento fundamental na busca da excelência. 4

Portanto, temos a obra literária do humanismo médico, o Corpus Hipocratium, que preconiza valores como o sigilo profissional, o benefício incondicional ao paciente, o absoluto respeito à vida humana e à moralidade pessoal, bem como a vida profissional baseada na deontologia profissional. 5

Considera-se esse texto - tão estudado e comentado - o espelho do bom profissional, e um marco na excelência ética, que permanece ao longo de 25 séculos, como documento de teor de defesa da ética dos deveres da profissão. A conduta, dele proveniente, manteve o paradigma de excelência profissional, respeitando os direitos das pessoas, e levando hoje a extensão da autonomia e da excelência para além do sentido paternalista.

A literatura ao longo dos séculos considera como determinante da ciência médica as influências da cultura grega antiga e o cristianismo pela identificação de seus princípios morais de forma abrangente e sistemática.

Ademais, desconsiderar o sistema de princípios morais - pois devem ser entendidos em conjunto seria reconhecer princípios auto-suficientes e absolutos. Portanto, não se pode reconhecer o more geométrico, que redunda em princípios absolutos, vez que a própria existência de um princípio fica a depender do conjunto de valores éticos e morais, sendo necessário limitações que permitam a convivência harmônica e sistemática dos princípios.

A ética de Aristóteles, assim como a de Platão, está unida à sua filosofia política, já que para ele como para seu mestre - a comunidade social e política é o meio necessário da moral. Somente nela pode realizar-se o ideal da vida teórica na qual se baseia a felicidade. 6 Nos aspectos mais importantes da ética platônica, apresenta-se um idealismo moral, de que a virtude vale tanto quanto a felicidade e também que o problema moral coletivo. Platão representa a continuidade do desenvolvido por Sócrates, em que o fundamental é o saber a respeito do homem.

A ética epicurista entra em cena com a decadência da ética grega e romana, que primava pela tese do homem com o encontro do bem, podendo encontrar em si próprio a paz da alma. A ética epicurista inclina-se para um sentido individualista, que tende a ser egocêntrico, e certo utilitarismo. A conduta é problema pessoal, não coletivo. Ao sábio interessam seu bem-estar e sua virtude, não a dos outros. A pessoa deve procurar seu próprio bem, sem se preocupar com os outros. Os homens viviam como feras, à margem da lei e decidiram unir-se para por um paradeiro naquele estado de beligerância. Surgiu assim a justiça, conceito negativo de não prejudicar os semelhantes, em troca do dever recíproco e idêntico destes. ${ }^{7}$

A ética cristã - como a filosofia cristã em geral parte de um conjunto de verdades reveladas a respeito de Deus, das relações do homem com o seu criador e do modo de vida prático que o homem deve seguir para obter a salvação do outro mundo. $6 \mathrm{O}$ afastamento do pensamento grego antigo, fica evidente quando Santo Agostinho descreve o amor bem como a vontade na visão de Santo Tomás de Aquino: o fim da vida humana é a bem aventurança em felicidade, que consiste essencialmente na visão imediata de Deus.

O filósofo Immanuel Kant denominou o mundo que experimentamos por meio dos nossos sentidos de mundo fenomenal e a realidade além dele de mundo numênico. A palavra alemã para isto é traduzida aproximadamente como a coisa em si mesma. 8

Por conseguinte, a filosofia Kantiana estendeu a concepção numênica ao homem, percebendo-o como o fim em si mesmo. Assim sendo, determinou a máxima da ação humana, denominada de imperativo categórico, que funciona com a perspectiva de uma consistência de deveres em que as pessoas deveriam ser tratadas com base no respeito, dignidade a qual todos tem direito.

Para o utilitarista clássico uma ação é considerada correta se, em comparação com uma ação alternativa, produzir um aumento equiparável, ou maior, da felicidade de todos a quem atinge; se não o produzir, é considerada errada. As consequências da ação variam segundo as circunstâncias nas quais ela é praticada. Daí não ser possível acusar propriamente um utilitarista de ser pouco realista nem de aderir rigidamente a ideais que desafiem a experiência prática. Dependendo das consequências do ato de mentir, o utilitarista irá considerá-lo mau em algumas circunstancias, e bom em outras. ${ }^{9}$ Os primeiros e principais filósofos da teoria utilitarista foram Jeremy Bentham (1748-1832) e John Stuart Mill (1806-1873) que consideram de forma concreta que os médicos são obrigados a considerar todos os 
fatos e consequências possíveis à luz da melhor informação disponível sobre suas possibilidades de alcance, definindo assim a medida cabível a promoção da felicidade. A teoria visa à produção da medida mais favorável ao paciente em comparação as demais, de acordo com as consequências analisadas a luz do caso concreto. Portanto, o utilitarismo não se distancia da prática forense em favor de ideais abstratos e entendimentos que proferem a medida ética como aquela sem falhas (perfeita). Percebe-se que em cada conduta humana são verificadas consequências danosas ou não, é irreal entender uma conduta que seja totalmente ética de forma estática, a qualquer caso concreto. As diversas manifestações do comportamento humano devem ser equiparadas, em busca da verificação da conduta que transmite um maior sentido de ética em determinada situação, seleciona-se a que implica menor sofrimento e promove a felicidade.

$\mathrm{O}$ estudo da ética no século XX, é pautado nos valores morais e humanistas dos clássicos, como a "racionalidade prática", a "deliberação" e a "prudência"; em especial temos uma redescoberta de Aristóteles em relação à teoria da ética com um retorno reflexivo. 4

Esse estilo geral de pensamento ético do século XX teve sua primeira aplicação sistemática no campo da bioética por Beauchamp e Childress. ${ }^{4}$ É de interesse saber que Beauchamp é filósofo e Childress é teólogo, o que não os impediu de redigir essa obra em colaboração, precisamente porque as éticas teológicas da autonomia não resultam em absoluto incompatíveis com o pensamento ético filosófico atual, que propugna pela consideração dos direitos humanos de forma distributiva. Em seus estudos, elaboraram um sistema de quatro princípios denominados respectivamente "autonomia", "beneficência", "não maleficência" e "justiça". 4

Um princípio absoluto seria determinador dos demais, e por ser absoluto, não comportaria reservas, o que demonstra a impossibilidade de seu reconhecimento por ser discordante de um sistema de concepção moralista. Os princípios devem comportar reservas, uns com relação aos demais, e a depender do caso concreto será definida a medida a ser adotada, garantindo assim, a convivência harmônica e interdependente dos mesmos na defesa da dignidade do ser humano. ${ }^{4}$

Foram assim considerados, princípios não absolutos que podem ser definidos na prática da bioética em cada situação com muito cuidado, para fazer valer os critérios da filosofia voltada à observação das circunstâncias concretas diante dos valores determinantes dos tempos atuais, aplicando-se os conceitos de Aristóteles na forma de deliberação e prudência, analisando cada situação em detalhes, com a visão atual que permite a participação de todos os implicados por uma decisão, fazendo com que a deliberação seja participativa, coerentes assim com a proposta dos Comitês de Ética em Pesquisa.

\section{Importância das teorias éticas na prática da bioética}

É evidente que a teoria ética nasce, em primeiro lugar, da necessidade de justificar racionalmente as opções morais, diante da própria consciência e diante dos demais. A elaboração teórica da moralidade nasce, em primeiro lugar, da nossa necessidade de compreendê-la a luz da própria racionalidade. Por ser a teoria um complexo integrado de princípios éticos, coerentes e fundamentais, o conhecimento das teorias éticas é essencial para reflexão, nas diversas áreas, quando se precisa do estudo dos métodos e conclusões destas referidas teorias, entendimento da casuística quando chegamos a um consenso moral sobre um caso. Essa necessidade de justificação torna-se mais premente e necessária nas situações de conflito, quando parece impossível cumprir todas as exigências de moralidade, ou diante do desafio que se estabelece quando as próprias convicções morais se confrontam com convicções distintas e até contraditórias. 10

A bioética, em seu início, defrontou-se com dilemas éticos criados pelo desenvolvimento da medicina. Pesquisa em seres humanos, uso humano da tecnologia, perguntas sobre a morte e o morrer são algumas áreas sensíveis dos anos 1990. As questões originais da bioética se expandiram para problemas relacionados com os valores nas diversas profissões de saúde mental. Grande número de temas sociais foi introduzido na abrangência da temática da bioética, tais como a saúde pública, alocação dos recursos em saúde, saúde da mulher, questão populacional e ecologia, para lembrar alguns. ${ }^{11}$

Desde os primórdios, pensou-se na bioética como fonte de normas, regras gerais e princípios, cujo objetivo principal seria o de disciplinar eticamente o trabalho de investigação científica e o de aplicação dos seus resultados, protegendo a biologia das ameaças desumanizadoras. A própria comunidade científica reconheceu essa necessidade, fazendo com que os princípios da bioética constituíssem, nas suas formulações iniciais, uma espécie de código de ética profissional para cientistas e pesquisadores. 12

Quer se trate de casos clínicos singulares a serem resolvidos, de pesquisas a serem avaliadas, de dire- 
trizes a serem elaboradas, de políticas de saúde a serem estabelecidas, a bioética diz respeito à decisão e à ação, uma vez que a reflexão conduz a elas. Com isto, colocam-se em ação processos de decisão e estratégias de ação estudadas por diversas disciplinas. ${ }^{13}$

A bioética seria então, um conjunto de reflexões filosóficas e morais sobre a vida em geral e sobre as práticas médicas em particular. Para tanto, abarcaria pesquisas multidisciplinares, envolvendo-se nas áreas antropológica, filosófica, teológica, sociológica, genética, médica, biológica, psicológica, ecológica, jurídica, política etc. Buscaria solucionar problemas individuais e coletivos derivados da biologia molecular, da embriológia, da engenharia genética, da medicina, da biotecnologia etc., decidindo sobre a vida, a morte, a saúde, a identidade ou integridade física e psíquica, procurando analisar eticamente aqueles problemas, para que a biossegurança e o direito possam estabelecer limites a biotecnociencia, impedir quaisquer abusos e proteger os direitos fundamentais das pessoas das futuras gerações. 14

Á guisa de conclusão diríamos que a bioética nasce de um sentimento de responsabilidade diante dos desafios de sustentar e melhorar as condições de vida humana nos processos contemporâneos. No enfrentamento de suas múltiplas questões, ela necessita de referenciais teóricos de fundo para postulados de tal responsabilidade; mas supõe também convicções espirituais que confirmam nas suas teorias um dinamismo voltado para proteger e defender a vida. 15

$\mathrm{Na}$ medida em que a bioética impõe uma reflexão acerca das condutas humanas, tanto sob o ponto de vista da responsabilidade interpessoal como geracional, propondo escolhas éticas, e por que não dizer políticas, passa a resgatar o espaço ético na sociedade como uma nova ação cultural essencial à proteção da própria humanidade. 16

Ao abordar os problemas de julgamento moral em bioética, temos dois princípios morais fundamentais, o consentimento e a beneficência. Seu caráter reflete a circunstancia de que são princípios para resolver disputas morais entre os indivíduos que não compartilham uma visão moral comum. Eles nos orientam em meio à divisão moral do pluralismo secular. Sustentam a possibilidade de discurso moral em sociedades pluralistas seculares onde não se pode estabelecer um sentido moral. 17

Por outro lado, parece evidente que a experiência nazista e o julgamento de Nuremberg excitaram a vigilância social contra os atrevimentos científicos e suscitaram um corpo de recomendações e de normas jurídicas, destinadas a conter a investigação dentro de limites aceitáveis, qualquer que seja o conteúdo concreto que esta expressão assuma, nos vários ambientes culturais em que a investigação médica se desenvolve. 18

Os campos de concentração nazista, denotando as atrocidades e crimes contra a humanidade, não foram casos isolados na história da pesquisa médica envolvendo seres humanos.

E desde o Código de Nuremberg, o documento mais importante de caráter internacional foi $\mathrm{o}$ Relatório Belmont, divulgado na década de 1970, que estabeleceu princípios para o norteamento e a regulamentação da pesquisa médica, ressaltando o respeito à dignidade da pessoa e os princípios da beneficência e justiça.

\section{Considerações finais}

Partindo-se da análise das circunstâncias históricas, é possível a percepção e fixação do nascimento dos princípios da bioética e seu entendimento, que conduzem a sua compreensão, a partir da tradição vinda de todas as disciplinas em uma forma construtiva nova, não podendo, no entanto, desvincular-se dos conhecimentos morais clássicos, como os da filosofia e da teologia.

Não existe uma moral uniforme e comum a todos os cidadãos, coexistem com seus conceitos a possibilidade de existência simultânea de diversas teorias na bioética, cujas aplicações podem conduzir a soluções diversas para os possíveis conflitos éticos, levando-se em conta a busca de uma responsabilidade solidária através de conceitos fundamentais.

Por não ser o conhecimento estático no tempo, há sempre um compromisso renovador e mesmo inovador no existir ético, quando do partilhamento de seus objetivos.

A análise de casos individuais, indispensável e essencial à reflexão ética, trás consigo a discussão de suas teorias e princípios, permitindo o aperfeiçoamento nas análises sobre condutas a serem seguidas, respeitando-se a construção científica de ordem moral e procurando sempre a evolução do homem. Desta forma há, uma relação dinâmica ante situações que se renovam ou inovam, considerando-se as mutações sociais e avanços tecnológicos, não podendo consistir apenas em uma ética clínica independente de orientações teóricas, mas que enfrente e atualize os desafios dos casos concretos ou reais, indispensáveis à promoção e fundamentação da vida moral e a prática clínica.

A ética assim entendida não é reservada apenas aos profissionais médicos, pois está relacionada a 
uma decisão múltipla de destaque a casos concretos, onde são necessárias indispensáveis reflexões e indagações, sempre respeitando o princípio da liberdade em relação à saúde, a partir de uma atividade ética inovadora, como consequência das ações clínicas diárias e de longo prazo.

Fundamental é um novo conceito de ética vinculado a uma bioética global, indispensável para a sobrevivência e a saúde do homem, com a ideia de responsabilidade de todos e de cada um, representado por um agir com respeito e cuidado, essencialmente ético, com a consciência de que sua

\section{Referências}

1. Lima Vaz HC. Ética e razão moderna. In: Lima Filho AA Pozzoli L. Ética do novo milênio: Busca do sentido na vida. 3 ed. São Paulo: LTr; 2005. p. 35-70.

2. Helferich C. História da filosofia. São Paulo: Martins Fontes; 2006.

3. Drummond JGF, Stepke FL. Fundamentos de uma antropologia bioética: $\mathrm{O}$ apropriado, o bom e o justo. São Paulo: Loyola; 2007.

4. Gracia D. Pensar a bioética: metas e desafios. 1 ed. São Paulo: Loyola; 2010

5. Pessini L. Siqueira JE. Hossne WS. Bioética: em tempo de incertezas. São Paulo: Loyola; 2010.

6. Vasquez AS. Ética. 26 ed. Rio de Janeiro: Civilização Brasileira; 2005.

7. Nalini JR. Ética geral e profissional. 6 ed. São Paulo: Ed Revista dos tribunais; 2008

8. Mannion J. O livro completo da filosofia. 5 ed. São Paulo: Madras; 2008.

9. Singer P. Vida ética. Rio de Janeiro: Ediouto; 2002.

10. Álvarez JJF. Para fundamentar a bioética: Teorias e paradigmas teóricos da bioética contemporânea. São Paulo: Loyola; 2005. compreensão não poderá estar atrelada a uma simples teoria, mas devendo portar-se com os princípios orientadores da filosofia para equilíbrio, acompanhamento e reformulação de ações, imprimindo um balizamento com base em casos reais. De lembrar assim, o pensamento de Potter, ${ }^{19}$ sobre bioética global e sobrevivência humana, para que a bioética seja entendida como uma nova ciência de competência interdisciplinar que combina a humanidade e a responsabilidade de forma a potencializar a proteção do ser humano.

11. Conti MCS. Biodireito: A norma da vida. Rio de Janeiro: Forense; 2004.

12. Catão MO. Biodireito: Transplante de órgãos humanos e direitos da personalidade. São Paulo: Madras; 2004

13. Durand G. Introdução geral à bioética: História, conceitos e instrumentos. São Paulo: Loyola; 2003.

14. Diniz MH. O estado atual do biodireito. 2 ed. São Paulo: Saraiva; 2002.

15. Anjos MF. Bioética: abrangência e dinamismo. In: Barchifontaine CP, Pessini L, orgs. Bioética alguns desafios. São Paulo: Loyola; 2001. p. 34

16. Gomes RR. A relevância da bioética na construção do novo paradigma da filiação na ordem jurídica nacional: Normas internacionais da bioética. In: Leite EO. Grandes temas da atualidade: Bioética e biodireito. Rio de Janeiro: Forense; 2004. p. 337-55.

17. Engelhardt HTJ. Fundamentos da bioética. São Paulo: Loyola; 1996.

18. Oliveira G. Temas de direito da medicina. Coimbra: Coimbra Editora; 1999.

19. Potter VR. Bioethics: bridge to the future, Englewood Cliffs (N.J.)., Prentice-Hall. 1971: VII - VIII.

Recebido em 28 de junho de 2010

Versão final apresentada em 1 de dezembro de 2010

Aprovado em 13 de dezembro de 2010 